\title{
Group A streptococcal pharyngitis
}

\author{
Lok-Yee Joyce Li, ${ }^{1,2}$ Shin-Yi Wang, ${ }^{3}$ Cheng-Yu Tsai, ${ }^{4}$ Cheng-Jung Wu (i) 5,6
}

'Department of Medicine, Shin Kong Wu Ho Su Memorial Hospital, Taipei, Taiwan ${ }^{2}$ School of Medicine, Taipei Medical University College of Medicine, Taipei, Taiwan ${ }^{3}$ National Taiwan University Hospital Hsinchu Branch, Hsinchu, Taiwan

${ }^{4}$ Department of Civil and Environmental Engineering, Imperial College London, London, UK

${ }^{5}$ Department of Otolaryngology, Taipei Medical University Shuang Ho Hospital Ministry of Health and Welfare, New Taipei City, Taiwan

${ }^{6}$ National Yang Ming Chiao Tung University, Hsinchu, Taiwan

\section{Correspondence to}

Dr Cheng-Jung Wu;

B101090126@tmu.edu.tw

Accepted 20 July 2021

\section{DESCRIPTION}

A 6-year-old boy presented to the emergency department with severe throat pain and raging fever for 1 day. The patient was unable to eat solids foods because of pain. On physical examination, cervical node lymphadenopathy, a swollen uvula and palatal petechiae were noted (figure 1). The rapid strep test is done to help quickly determine whether a sore throat is caused by a streptococcal infection. The result of a throat culture is compatible with the diagnosis of group A streptococcal pharyngitis. The patient was treated with penicillin and topical analgesia. The primary reason to treat this self-limited illness with antibiotics is to reduce the risk of complications such as rheumatic fever, meningitis, endocarditis and retropharyngeal abscess. ${ }^{1-3}$ Antibiotic therapy also reduces the risk of suppurative complications of streptococcal infection. ${ }^{4}$ A Cochrane review

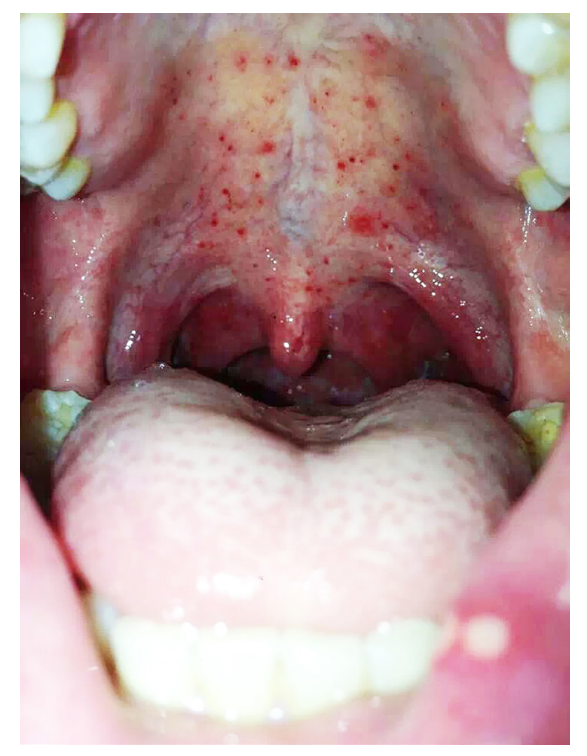

Figure 1 Palatal petechiae were noted.

\section{Learning points}

- Treat this self-limited illness with antibiotics which could reduce the risk of complications such as rheumatic fever, meningitis, endocarditis and retropharyngeal abscess.

- Common symptoms include cervical node lymphadenopathy, a swollen uvula and palatal petechiae.

of randomised, placebo-controlled trials showed that antibiotic therapy significantly reduced the risks of acute otitis media and peritonsillar abscess. ${ }^{5}$ Treatment with antibiotics is effective if given within 9 days of the onset of symptoms.

Contributors C-JW and L-YJL performed the experiments. L-YJL, S-YW and C-YT contributed reagents/materials/analysis tools. L-YJL wrote the paper.

Funding The authors have not declared a specific grant for this research from any funding agency in the public, commercial or not-for-profit sectors.

Competing interests None declared.

Patient consent for publication Parental/guardian consent obtained.

Provenance and peer review Not commissioned; externally peer reviewed.

ORCID iD

Cheng-Jung Wu http://orcid.org/0000-0002-7443-2119

\section{REFERENCES}

1 Sharp EA, Linn A, Zitelli BJ. Group A streptococcal pharyngitis associated with primary peritonitis. BMJ Case Rep 2019;12:e229186.

2 Mação P, Cancelinha C, Lopes P, et al. An 11-year-old boy with pharyngitis and cough: Lemierre syndrome. BMJ Case Rep 2013;2013:bcr2012008527.

3 Bhavsar SM, Shust GF. Invasive group G streptococcal infection in a paediatric patient. BMJ Case Rep 2016;2016:bcr2016217790.

4 Wessels MR. Clinical practice. Streptococcal pharyngitis. N Engl J Med 2011;364:648-55.

5 Del Mar CB, Glasziou PP, Spinks AB. Antibiotics for sore throat. Cochrane Database Syst Rev 2006:CD000023.

Copyright 2021 BMJ Publishing Group. All rights reserved. For permission to reuse any of this content visit

https://www.bmj.com/company/products-services/rights-and-licensing/permissions/

BMJ Case Report Fellows may re-use this article for personal use and teaching without any further permission.

Become a Fellow of BMJ Case Reports today and you can:

- Submit as many cases as you like

- Enjoy fast sympathetic peer review and rapid publication of accepted articles

- Access all the published articles

- Re-use any of the published material for personal use and teaching without further permission

Customer Service

If you have any further queries about your subscription, please contact our customer services team on +44 (0) 2071111105 or via email at support@bmj.com.

Visit casereports.bmj.com for more articles like this and to become a Fellow 